\title{
Interfacial Control of Creep Deformation in Ultrafine Lamellar TiAl
}

\author{
L. M. Hsiung
}

This article was submitted to 2002 Materials Research Society Fall Meeting, Boston, MA, December 1-6, 2002

\section{November 26, 2002}

U.S. Department of Energy

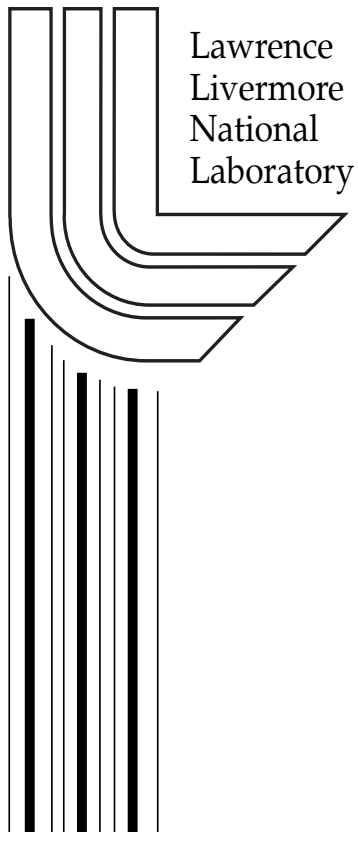




\section{DISCLAIMER}

This document was prepared as an account of work sponsored by an agency of the United States Government. Neither the United States Government nor the University of California nor any of their employees, makes any warranty, express or implied, or assumes any legal liability or responsibility for the accuracy, completeness, or usefulness of any information, apparatus, product, or process disclosed, or represents that its use would not infringe privately owned rights. Reference herein to any specific commercial product, process, or service by trade name, trademark, manufacturer, or otherwise, does not necessarily constitute or imply its endorsement, recommendation, or favoring by the United States Government or the University of California. The views and opinions of authors expressed herein do not necessarily state or reflect those of the United States Government or the University of California, and shall not be used for advertising or product endorsement purposes.

This is a preprint of a paper intended for publication in a journal or proceedings. Since changes may be made before publication, this preprint is made available with the understanding that it will not be cited or reproduced without the permission of the author.

This report has been reproduced directly from the best available copy.

Available electronically at http://www.doc.gov/bridge

Available for a processing fee to U.S. Department of Energy

And its contractors in paper from

U.S. Department of Energy

Office of Scientific and Technical Information

P.O. Box 62

Oak Ridge, TN 37831-0062

Telephone: (865) 576-8401

Facsimile: (865) 576-5728

E-mail: reports@adonis.osti.gov

Available for the sale to the public from

U.S. Department of Commerce

National Technical Information Service

5285 Port Royal Road

Springfield, VA 22161

Telephone: (800) 553-6847

Facsimile: (703) 605-6900

E-mail: orders@ntis.fedworld.gov

Online ordering: http://www.ntis.gov/ordering.htm

\section{OR}

Lawrence Livermore National Laboratory

Technical Information Department's Digital Library

http://www.llnl.gov/tid/Library.html 


\title{
Interfacial Control of Creep Deformation in Ultrafine Lamellar TiAl
}

UCRL-JC-151138

\author{
L. M. Hsiung \\ University of California, Lawrence Livermore National Laboratory \\ Chemistry and Materials Science Directorate \\ Livermore, CA 94551-9900, U.S.A.
}

\begin{abstract}
Solute effect on the creep resistance of two-phase lamellar TiAl with an ultrafine microstructure creepdeformed in a low-stress $(\boldsymbol{L S})$ creep regime [where a linear creep behavior was observed] has been investigated. The resulted deformation substructure and in-situ TEM experiment revealed that interface sliding by the motion of pre-existing interfacial dislocations is the predominant deformation mechanism in $\boldsymbol{L S}$ creep regime. Solute segregation at lamellar interfaces and interfacial precipitation caused by the solute segregation result in a beneficial effect on the creep resistance of ultrafine lamellar TiAl in $\boldsymbol{L S}$ creep regime.
\end{abstract}

\section{INTRODUCTION}

Two-phase [TiAl $\left(\gamma-\mathrm{L}_{0}\right)$ and $\mathrm{Ti}_{3} \mathrm{Al}\left(\alpha_{2}\right.$-DO19)] lamellar TiAl alloys have recently attracted a great attention because of their low density ( $\rho=3.9 \mathrm{~g} / \mathrm{cc}$ ), high specific strength, adequate oxidation resistance, and good combination of ambient-temperature and elevated-temperature mechanical properties, which are of interest for aerospace and transportation applications such as high-temperature components in turbine and combustion engines. Through alloy design and microstructural optimization, significant progress has been made to improve both room-temperature ductility/toughness and high-temperature creep resistance of the alloys [1-5]. Previous research has revealed that the alloys fabricated by hot extrusion of gas-atomized $\mathrm{TiAl}$ powder at $1400^{\circ} \mathrm{C}$ can form refined lamellar microstructures in association with interlocking colony boundaries through a shear-assisted eutectoid transformation induced by hot-extrusion process [6]. The hot-extruded lamellar alloys provide a better combination of room temperature and high-temperature mechanical properties than those of lamellar TiAl alloys fabricated by conventional ingot metallurgy. Accordingly, there is of great interest to further refine lamellar spacing of the alloys to submicron or nanometer length-scales to develop TiAl nanophase composites for engineering applications. A recent report of the formation of nanoscale lamellae (with lamellar spacing in the order of 5 to $10 \mathrm{~nm}$ ) within a water-quenched TiAl alloy [7] revealed the feasibility of materializing the idea of fabricating TiAl nanophase composites. However, in parallel to make an effort for developing TiAl nanophase composites, there is a need to understand if further refinement of the lamellar microstructures would lead to adverse effects on high-temperature creep properties. A previous investigation [8] on the creep behavior of a Ti$47 \mathrm{Al}-2 \mathrm{Cr}-2 \mathrm{Nb}$ (at.\%) alloy with a refined lamellar microstructure revealed that there existed two distinct creep

regimes, where a nearly linear creep behavior [i.e. $\dot{\varepsilon}$ (steady-state creep rate) $=k \sigma^{n}$, where $\sigma$ is applied creep stress and $n \approx 1$ ] was observed in low-stress $(\boldsymbol{L S})$ regime (i.e. $\sigma<300 \mathrm{MPa}$ at $760^{\circ} \mathrm{C}$ ), and power-law break down $(n>$ 6) was observed in high-stress $(\boldsymbol{H S})$ regime (i.e. $\sigma>300 \mathrm{MPa}$ at $760^{\circ} \mathrm{C}$ ). TEM investigation of deformation substructures within creep-deformed specimens has revealed the occurrence of interface sliding in $\boldsymbol{L S}$ regime and deformation twinning in $\boldsymbol{H} \boldsymbol{S}$ regime, which has led us to propose that interface sliding associated with viscous glide of pre-existing interfacial dislocations is the predominant creep mechanism in $\boldsymbol{L} \boldsymbol{S}$ regime, and interfaceactivated deformation twinning in $\gamma$ lamellae is the predominant creep mechanism in $\boldsymbol{H S}$ regime [9, 10]. Furthermore, it is also suggested that the solute atoms segregated at lamellar interfaces can act as short-range barriers to drag the motion of interfacial dislocation arrays during interface sliding. It is also anticipated that more effective barriers to impede the interface sliding can be obtained by interfacial precipitation resulting from the solute segregation. Accordingly, the investigation was extended to investigate the effect of alloying modification on the creep property of refined lamellar TiAl. Emphasis will be placed upon the effect of solute segregation on the creep resistance in $\boldsymbol{L S}$ regime in order to facilitate the effort of developing TiAl nanophase composites for high-temperature applications. 


\section{EXPERIMENTAL DETAILS}

TiAl alloys with nominal compositions of Ti-47Al-2Cr-2Nb and Ti-47Al-2Cr-1Nb-0.8Ta-0.2W-0.15B (at.\%) were chosen for current study. The alloys were fabricated at Oak Ridge National Laboratory by a powder metallurgy process, which involves a hot-extrusion (16:1 ratio) of gas-atomized titanium aluminide powder (particle size: - 200 mesh) canned in molybdenum billets and were subsequently hot-extruded at $1400^{\circ} \mathrm{C}$. Test specimens with a gauge dimension of $24.4 \times 5.08 \times 1.52 \mathrm{~mm}$ were prepared from the annealed alloys by electrical discharge machining. Creep tests were conducted in a dead-load creep machine with a lever arm ratio of 16:1. Tests were performed in air in a split furnace with three zones at $760{ }^{\circ} \mathrm{C}$ and $815^{\circ} \mathrm{C}$. The deformation substructures of tested specimens creep deformed in both $L S$ and $H S$ regimes were investigated. In-situ TEM experiment was conducted by electron-beam heating of a pre-crept sample $\left(138 \mathrm{MPa}, 760^{\circ} \mathrm{C}\right)$ to study interfacial dislocation motion. TEM foils were prepared by twinjet electropolishing in a solution of $60 \mathrm{vol} \%$ methanol, 35 vol. \% butyl alcohol and 5 vol. $\%$ perchloric acid at $\sim 15 \mathrm{~V}$ and $-30^{\circ} \mathrm{C}$. The microstructures of the creepdeformed alloys were examined using a JEOL-200CX transmission electron microscope equipped with a doubletilt goniometer stage.

\section{DISCUSSION}

\section{Microstructures of As-extruded alloys}

Near fully lamellar microstructures [containing TiAl $\left(\gamma-\mathrm{L}_{0}\right)$ and $\mathrm{Ti}_{3} \mathrm{Al}\left(\alpha_{2}\right.$-DO19) lamellae] with interlocking colony boundaries were developed within both Ti-47Al-2Cr-2Nb and Ti-47Al-2Cr-1Nb-0.8Ta-0.2W-0.15B alloys hot extruded at $1400^{\circ} \mathrm{C}$. Typical lamellar microstructures of Ti-47Al-2Cr-2Nb and TiAl-47Al-2Cr-1Nb-0.8Ta$0.2 \mathrm{~W}-0.15 \mathrm{~B}$ alloys are shown in Figs. 1 (a) and (b), respectively. Similar colony grain sizes $(<100 \mu \mathrm{m})$ and lamella widths were observed within the lamellar alloys. The width of $\gamma$ lamellae varies between $100 \mathrm{~nm}$ and 350 $\mathrm{nm}$, and the width of $\alpha_{2}$ lamellae varies between $10 \mathrm{~nm}$ and $50 \mathrm{~nm}$. These values are considerably finer than those in lamellar TiAl alloys fabricated by conventional processing techniques. In addition, as shown in Fig. 1 (c), interwoven-type colony boundaries were developed within these two lamellar alloys, which could effectively interlock the colony boundaries from rotation and sliding when deformed at elevated temperatures. In general, lamellar TiAl contains two types of lamellar interfaces within colony grains [11, 12]: (1) the $\gamma / \alpha_{2}$ interphase interface which has an orientation relationship: $(0001)_{\alpha 2} \|(111)_{\gamma}$ and $<11 \overline{2} 0>_{\alpha 2} \|<1 \overline{10}>_{\gamma}$ [which can be determined from the SAD pattern shown in Fig. 1(a)], and (2) the $\gamma / \gamma$ interfaces which include true twin, pseudo twin, and order-fault interfaces. Both pre-existing lattice dislocations $(L D)$ within $\gamma$ lamellae and a high density of intrinsic interfacial dislocations (ID) in lamellar interfaces were observed within as-fabricated lamellar TiAl [Fig. 1(d)]. While the intrinsic interfacial dislocations formed in semi-coherent $\gamma / \alpha_{2}$ interfaces are $1 / 6<112>$ or $1 / 3<112>$ type misfit dislocations, those on $\gamma / \gamma$ twin-related interfaces are $1 / 6[11 \overline{2}]$ type twinning dislocations or geometry necessary dislocations for accommodating the departure of true-twin interface from the exact (111) twin plane [13 - 15].

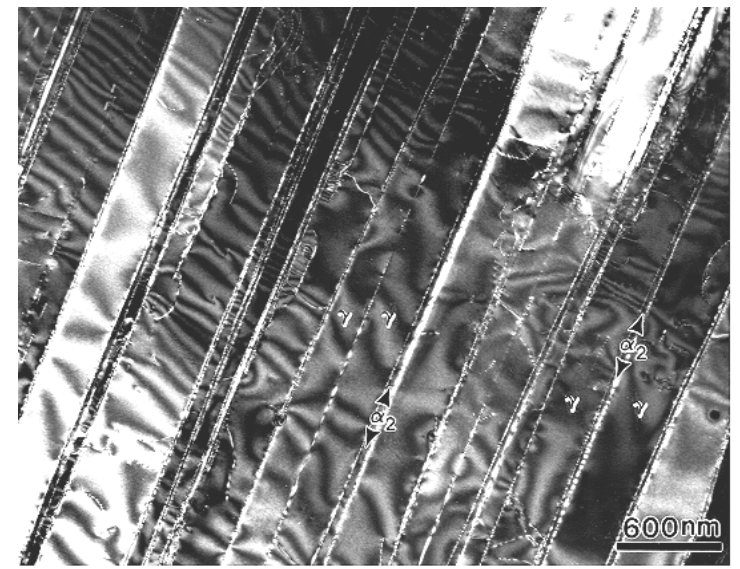

(a)

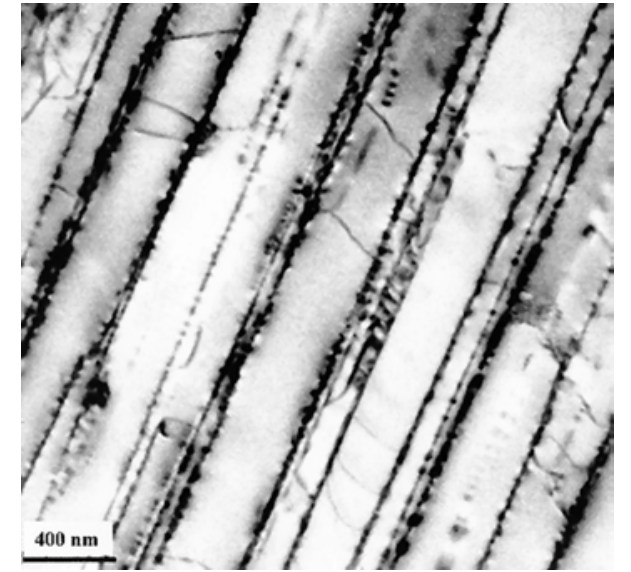

(b) 


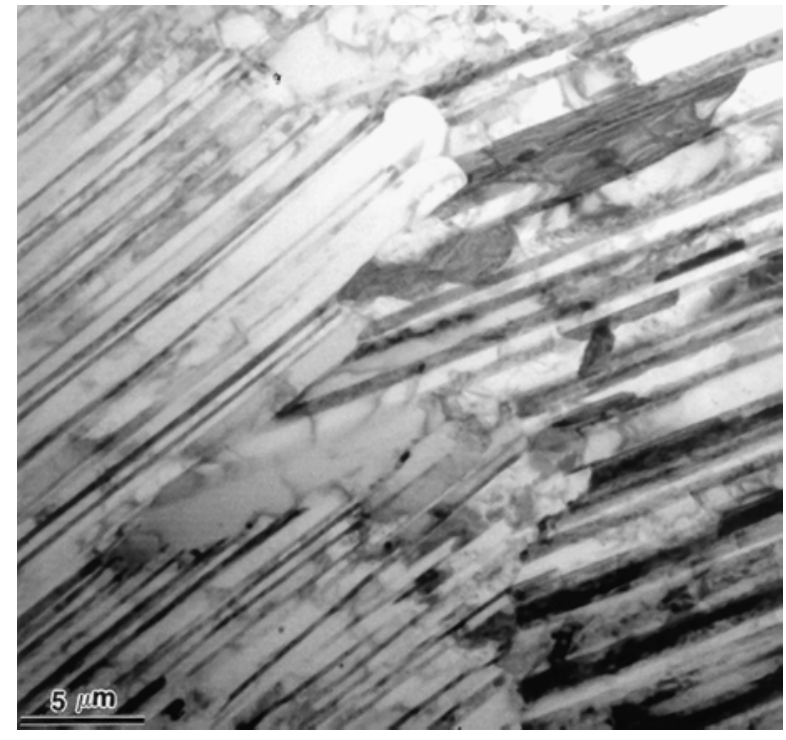

(c)

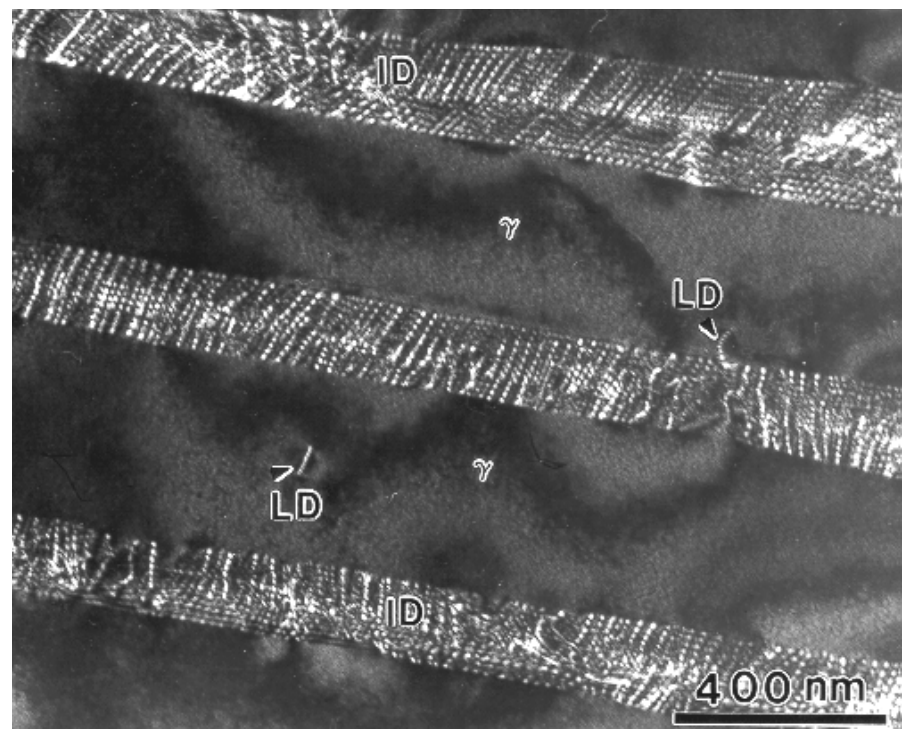

(d)

Fig. 1. (a) A weak-beam dark-field TEM image showing a typical lamellar microstructure observed from Ti-47Al-2Cr-2Nb extruded at $1400^{\circ} \mathrm{C}$, and an SAD pattern generated from the domain in (a) showing the phase relationships between $\gamma$ and $\alpha_{2}, \mathbf{Z}=[0 \overline{1} 1]_{\gamma} \|\left[01 \overline{1}_{0}\right]_{\alpha 2} ;$ (b) a bright-field TEM image showing a typical lamellar microstructure observed from Ti-47Al-2Cr-1Nb-0.8Ta- $0.2 \mathrm{~W}-0.15 \mathrm{~B}$ extruded at $1400^{\circ} \mathrm{C}$; (c) a bright-field TEM image showing a interwoven colony boundary in lamellar Ti-47Al-2Cr-1Nb$0.8 \mathrm{Ta}-0.2 \mathrm{~W}-0.15 \mathrm{~B}$; (d) a tilt view of lamellar microstructure showing a dislocation substructure within the lamellar alloy ( $L D$ denotes lattice dislocation, and $I D$ denotes interfacial dislocation).

\section{Creep data and deformation substructures}

Creep data of the refined lamellar Ti-47Al-2Cr-2Nb alloy tested at $760^{\circ} \mathrm{C}$ with a comparison of the creep data of conventionally processed TiAl alloys reported in the literature is shown in Fig. (a) [3]. The refined lamellar alloy demonstrates superior creep resistance among all in the high stress $(H S)$ regime and relatively better (although not the best) creep resistance in the low stress $(L S)$ regime. Since for engineering applications the structural components are mainly operated in $L S$ regime, further investigations were conducted to understand the underlying creep mechanism in $L S$ regime in order to improve the creep resistance of the lamellar alloy. By re-

plotting the data to correlate the power-law creep (i.e. $\dot{\varepsilon}=k \sigma^{n}$ ) as shown in Fig. (b), a nearly linear creep behavior ( $n \approx 1$, i.e. the steady-sate creep rate is nearly proportional to the applied stress) occurred in $L S$ regime $(<300$ $\mathrm{MPa})$, and power-law breakdown $(n \approx 7)$ took place in $H S$ regime $(>300 \mathrm{MPa})$. The corresponding deformation substructures of creep-deformed samples under conditions A (138 MPa in $L S$ regime) in Fig. 2(b) is shown in Fig. 3. In general, no significant increase in dislocation density was found within the specimen deformed in $L S$ regime, except that grain boundary ledges presumably formed as a result of interface sliding (caused by the motion of $I D$ arrays) are shown in Fig. 3. On the other hand, as reported in [10], both the emission of dislocations from lamellar interfaces and the formation of $\{111\}$ and $\{112\}$-type deformation twins $(D T)$ were observed within the specimen deformed in $H S$ regime. The above observations suggest that interface sliding is the predominant deformation mechanism in $L S$ regime, whereas the deformation of $\gamma$ lamellae by the emission of dislocations and deformation twins from lamellar interfaces becomes the predominant deformation mechanisms in $H S$ regime. 


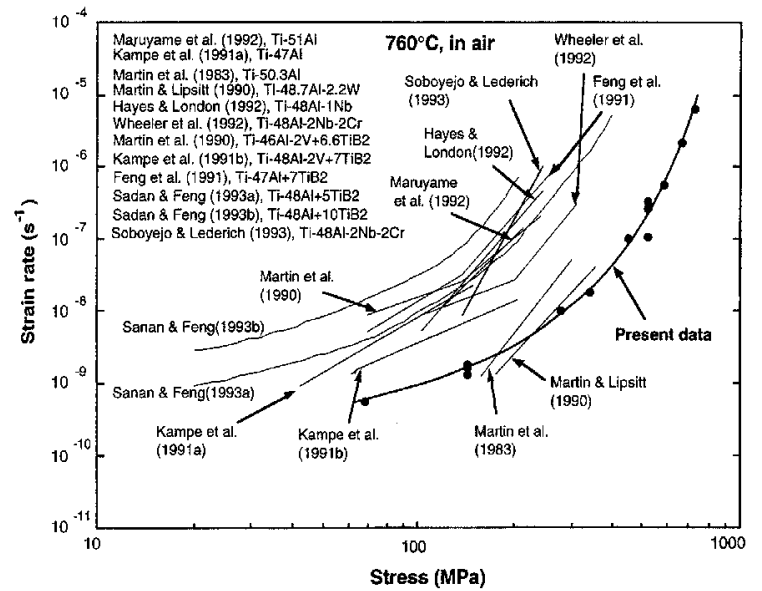

(a)

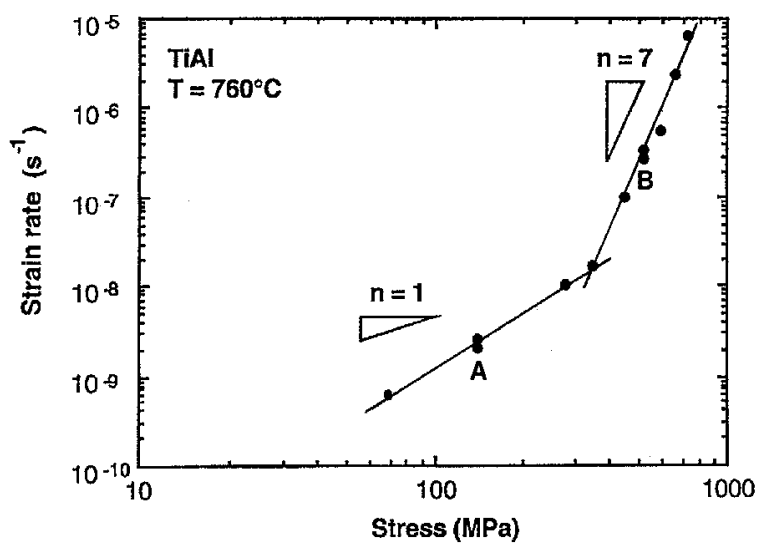

(b)

Fig. 2. (a) A comparison of the creep resistance at $760^{\circ} \mathrm{C}$ between the presently studied PM alloy and other TiAl alloys [3]; (b) steady-state creep rate plotted as a function of applied stress at $760^{\circ} \mathrm{C}$ showing that there existed two distinct creep regimes, i.e. low stress $(L S)$ and high stress $(H S)$ regimes.

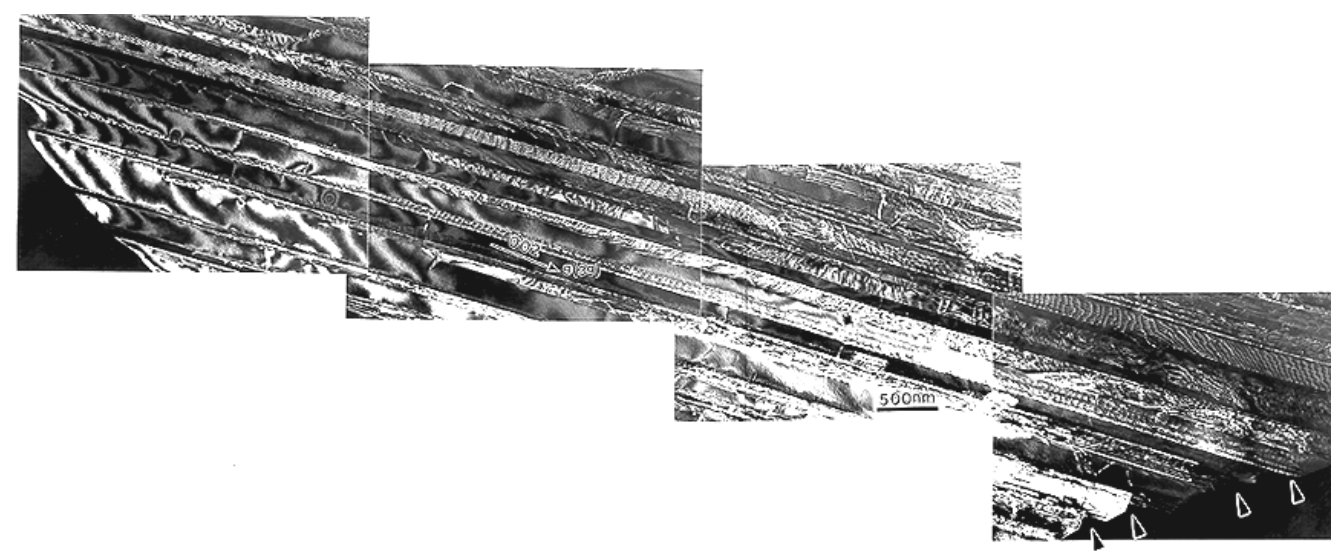

Fig. 3. A dark-field TEM image showing the formation of grain boundary ledges (marked by arrows) presumably caused interface sliding within a specimen creep-deformed at $760^{\circ} \mathrm{C}, 138 \mathrm{MPa}$.

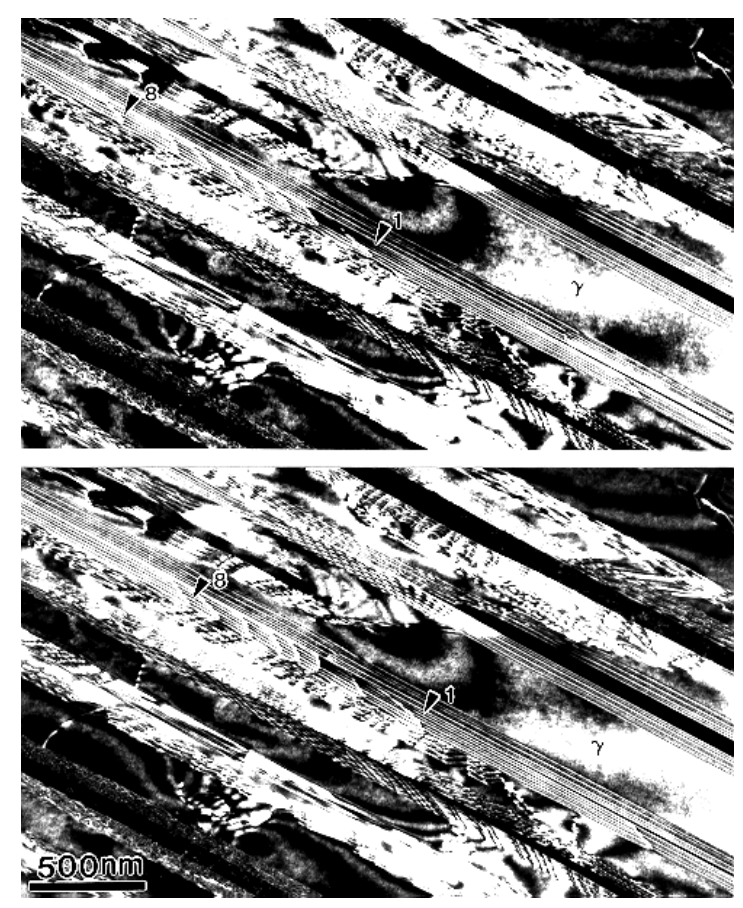

Fig. 4. Consecutive in-situ TEM images showing the motion of an interfacial dislocation array in a $\gamma / \gamma$ interface (time period for beam heating: $20 \mathrm{~s}$ ). 
Results of in-situ TEM experiment to demonstrate the cooperative motion of interfacial dislocations in lamellar TiAl under room-temperature straining conditions have been reported elsewhere [16]. Here, results of in-situ TEM experiment from a creep-deformed sample $\left(138 \mathrm{MPa}, 760^{\circ} \mathrm{C}\right)$ are presented to demonstrate the motion of interfacial dislocations under an electron-beam heating condition. It is noted that a local heating of TEM sample can be achieved by spotting the focused electron-beam (several micron meters in size) onto the region of interest in the sample. Figure 4 are two consecutive in-situ images showing the cooperative motion of a dislocation array (total eight interfacial dislocations in the array) in a $\gamma / \gamma$ interface during beam heating, and the array moved about $250 \mathrm{~nm}$ after beam heating for 20 seconds. The dislocation array stopped moving after re-spreading the beam onto a wide region of the TEM sample. It is also worthy to note that zigzag motion of the interfacial dislocations were observed during the experiment which presumably caused by the pinning-unpinning of dislocation lines from solute atoms during their movement. This observation supports the previously proposed creep mechanism [9]: interface sliding associated with a viscous glide of pre-existing interfacial dislocations is the predominant deformation mechanism in $L S$ regime. The interstitial atoms segregated at lamellar interfaces can act as shortrange barriers for the motion of interfacial dislocations and resulting in the viscous glide of interfacial dislocations at elevated temperatures. The high population of interfacial dislocations in lamellar interfaces can act as preferential sites for solute segregation. In fact, the segregation of W solute atoms at lamellar interfaces has recently been identified from a lamellar TiAl alloy by Liu et al. using a field-ion atom probe technique [17].

It is accordingly suggested that while further refining of lamellar spacing may increase creep resistance of lamellar TiAl in $H S$ regime by restraining $L D$ motion within constituent lamellae and impeding $I D$ motion by impinging $L D$ and $D T$ onto lamellar interfaces, it can cause an adverse effect on the creep resistance of lamellar TiAl in $L S$ regime. The creep resistance of refined lamellar TiAl in $L S$ regime may be promoted by reducing the mobility of interfacial dislocations by the segregation of low-diffusivity solutes such as Ta and $\mathrm{W}$ to impede the motion of interfacial dislocations. Although more rigorous investigations are needed for the effects of solute segregation at lamellar interfaces to the creep resistance of lamellar TiAl at $L S$ regime, a preliminary result demonstrating the promotion of creep resistance of lamellar TiAl by the addition of Ta, W, and B is shown in Fig. 5 (a). As can be seen clearly that steady state creep rates significantly decrease as a result of the solute additions of Ta, W, and B. Figure 5 (b) shows a preliminary result of TEM examination of the Ti-47Al-2Cr-1Nb-0.8Ta$0.2 \mathrm{~W}-0.15 \mathrm{~B}$ alloy sample creep-deformed at $70 \mathrm{MPa}$. It reveals the formation of $\mathrm{TiB}_{2}$-type boride particles at $\alpha_{2} / \gamma$ interfaces, but it is interesting to note that no such boride particles were found at $\gamma / \gamma$ interfaces. This suggests that solute segregation phenomenon is more pronounced at $\alpha_{2} / \gamma$ interfaces than at $\gamma / \gamma$ interface. Detail microanalysis of solute segregation at different lamellar interfaces is currently underway in order to facilitate the effort of developing advanced TiAl nanophase composites for high-temperature applications through the alloying modification of lamellar interfaces.

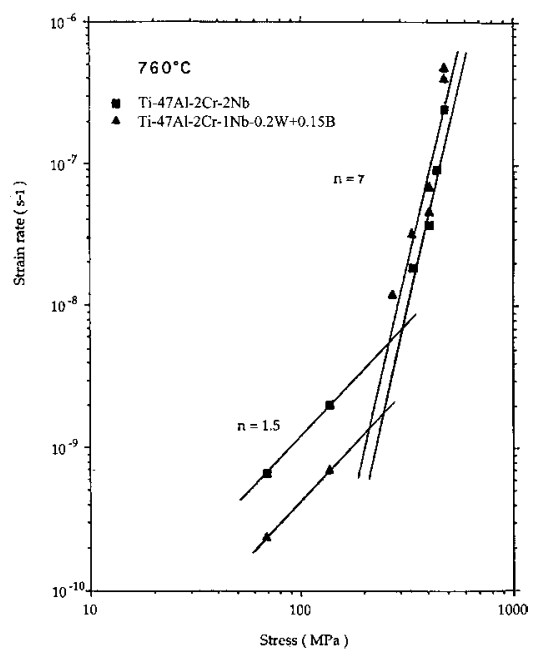

(a)

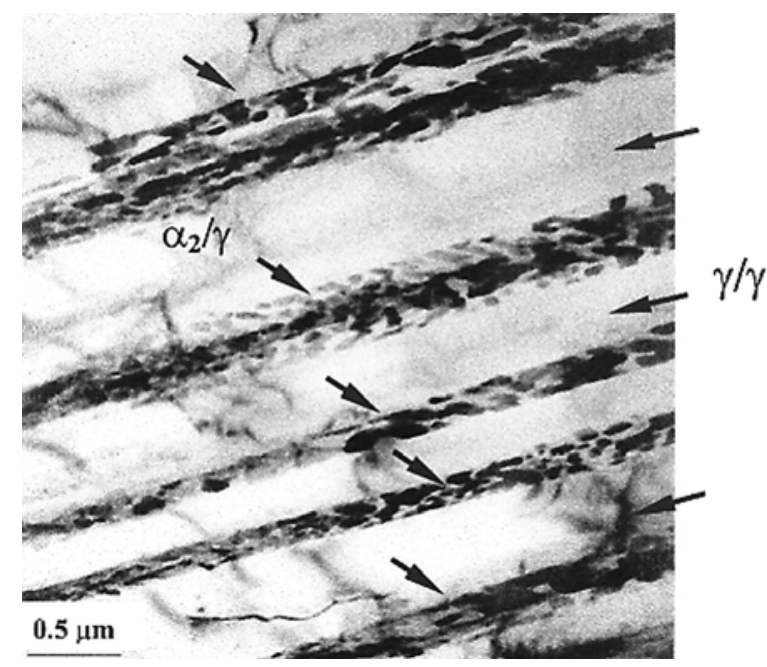

(b)

Fig. 5. (a) Creep data show the effects of alloying modification to the creep resistance of refined lamellar TiAl alloys in $L S$ regime at $760{ }^{\circ} \mathrm{C}$; (b) Bright-field TEM images showing the formation of $\mathrm{TiB}_{2}$-type boride particles at $\alpha_{2} / \gamma$ interfaces within a Ti-47Al-2Cr- $1 \mathrm{Nb}-0.8 \mathrm{Ta}-0.2 \mathrm{~W}-0.15 \mathrm{~B}$ alloy sample creep-deformed at $760^{\circ} \mathrm{C}, 70 \mathrm{MPa}$. 


\section{CONCLUSION}

A nearly linear creep behavior [i.e. $\dot{\varepsilon}=k \sigma^{n}, n \sim 1$ ] has been observed in both Ti-47Al-2Cr-2Nb and Ti-47Al$2 \mathrm{Cr}-1 \mathrm{Nb}-0.8 \mathrm{~W}-0.2 \mathrm{~W}-0.15 \mathrm{~B}$ alloys with an ultrafine lamellar microstructure ( $\gamma$ lamellae: $100-300 \mathrm{~nm}$ thick, $\alpha_{2}$ lamellae: $10-50 \mathrm{~nm}$ thick) creep-deformed at elevated temperatures with stresses below $300 \mathrm{MPa}$. The resulted deformation substructure and in-situ TEM experiment revealed that interface sliding by the motion of pre-existing interfacial dislocations is the predominant deformation mechanism. Since the operation and multiplication of lattice dislocations within both $\gamma$ and $\alpha_{2}$ lamellae are very limited at a low stress level as a result of the refined lamellar spacing, creep mechanisms based upon glide and/or climb of lattice dislocations become insignificant, instead the mobility of interfacial dislocation arrays on $\gamma / \alpha_{2}$ and $\gamma / \gamma$ interfaces becomes predominant. It has demonstrated that solute segregation at lamellar interfaces and interfacial precipitation caused by the solute segregation result in a beneficial effect on the creep resistance of ultrafine lamellar TiAl in low-stress creep regime as a result of effective pinning of the $\alpha_{2} / \gamma$ interfaces and decreasing the mobility of interfacial dislocations in the $\gamma / \gamma$ interfaces.

\section{ACKNOWLEDGEMENTS}

This work was performed under the auspices of the U.S. Department of Energy by University of California, Lawrence Livermore National Laboratory under contract No. W-7405-Eng-48. The author would like to thank Dr. T.G. Nieh for providing unpublished creep data and many helpful discussions during the course of this investigation. The author is also in debt to Dr. C. T. Liu of Oak Ridge National Laboratory for his technical guidance and providing the alloys used for this investigation.

\section{REFERENCES}

1. Y-W. Kim and D.M. Dimiduk, JOM, 43(8), 40 (1991).

2. Y -W. Kim, Acta Metall. Mater. 40, 1121 (1992).

3. J. N. Wang, A. J. Schwartz, T. G. Nieh, C. T. Liu, V. K. Sikka and D. R. Clemens, in Gamma

Titanium Aluminides, ed. Y-W. Kim et al., TMS (Warrendale, PA), 949, (1995).

4. C.T. Liu, J.H. Schneibel, P.J. Maziasz, J.L. Wright, D.S. Easton, Intermetallics 4, 429 (1996).

5. C. T. Liu, P. J. Maziasz, J. L. Wright, Mat. Res. Soc. Symp. Proc., 460, 83 (1997).

6. L.M. Hsiung, T.G. Nieh and D.R. Clemens, Scripta Mater., 36 (1997), 233.

7. K. Hono, E. Abe, T. Kumagai, H. Harada, Scripta Mater., 35, 495 (1996).

8. J. N. Wang and T. G. Nieh, Acta Mater., 46, 1887 (1998).

9. L. M. Hsiung and T. G. Nieh, Intermetallics 7, 821 (1999).

10. L.M. Hsiung, T.G. Nieh, B.W. Choi, and J. Wadsworth, Mater. Sci. Eng., A329-331, (2002), 637.

11. M. Yamaguchi, S.R. Nishitani, Y. Shirai, in High Temperature Aluminides and Intermetallics, ed.

S.H. Whang et al., TMS (Warrendale, PA), 63, 1990.

12. Y. Yamamoto, M. Takeyama, T. Matsuo, Mater. Sci. and Engrg., A329 - 331, 631 (2002).

13. G.J. Mahon and J.M. Howe, Metall. Trans. A, 21, 1655 (1990).

14. L. Zhao and K. Tangri, Acta Metall. Mater., 39, 2209.

15. L. M. Hsiung and T. G. Nieh, Mater. Sci. Engrg., A239-240, 438 (1997).

16. L. M. Hsiung, A. J. Schwartz and T. G. Nieh, Scripta Mater. 36, 1017 (1997).

17. C.T. Liu, P.J. Maziasz, D.J. Larson, in Interstitial and Substitutional Solute Effects in Intermetallics, ed. I. Baker et al., TMS (Warrendale, PA), 179 (1998).

18. M. De Graef, D.A. Hardwick, P.L. Martin, in Structural Intermetallics, ed. M.V. Nathal et al., TMS (Warrendale, PA), 177 (1993).

19. D.J. Larson, C.T. Liu, M.K. Miller, Intermetallics 5, 411 (1997).

20. C.T. Liu, J.L. Wright, S.C. Deevi, Mater. Sci. and Engrg., A329 - 331, 416 (2002). 